\title{
Moveable Worlds/Digital Scenographies
}

\author{
Johannes Birringer, Brunel University
}

\begin{abstract}
The mixed reality choreographic installation UKIYO, explored in this article, reflects an interest in scenographic practices that connect physical space to virtual worlds and explore how performers can move between material and immaterial spaces. The spatial design for UKIYO is inspired by Japanese hanamichi and western fashion runways, emphasizing the research production company's commitment to various creative cross-overs between movement languages, innovative wearable design for hellerauinteractive performance, acoustic and electronic sound processing and digital image objects that have a pastic as well as an imagistic/virtual dimension. while strongly lies in various forms of making art in order to visualize things that are not in themselves visual, or which connect visual and kinaesthetic/tactile/auditory experiences. The "Moveable Worlds" in this poetic essay are also reflections of the narrative spaces, subtexts and visual-auditory and kinaesthetic relationships in a mutating matrix of "installation" - spaces inviting the audience to follow their sensorial experiences, drawn near to the bodies of the dancers.
\end{abstract}

\section{Keywords}

mixed reality, choreographic installation,

screen spaces, virtual environment, audiophonics

\section{Floating}

The croaking of toads in the fields flooded by clear waters: I go on living thinking day and night about the moon that, unfaithful, floats from field to field.

(Hanaogi IV, print by I. Koryusai, 1785-89)

The architect Zaha Hadid is reported to have said "why stick to one when there are $360^{\circ}$ possible", and this has always seemed like a good idea when you start out designing a space for a dance. Dancing is like the moon light, charmingly evoked by 
the $18^{\text {th }}$ century courtesan Hanaogi in her calligraphy on transience and the fashionable life of beauty and display in the flashy world of the city. Most ephemeral and yet most sensual, dancing moves through space, becoming and always changing space of its appearances and dynamic potentials, moments to be perceived in space and through time. Our bodies were born to move, and we breathe and experience the world moving. The arrangement of theatre, where spectators are seated to be "stilled" in their sensing perception of movement, is an unnatural once, even as the histories of performance in many cultures show rather fascinating differences in the architectural visions that were brought to the construction of "containers" for action, choreography, singing, music, and the many forms of orchestration of sensory perception.

From the point of view of the perceiving audience, a proscenium stage, an empty black box as much as a cluttered "set," an installation or a site-specific performance location - they can all indicate containers, and the architecture of a theatre or the material design of space (the set) function as structuring devices for the event, and the relationships between the place, the artwork, and the audience. Scenography is a somewhat underrated craft, compared to the attention given to directors, choreographers, composers, playwrights and actors/dancers or musicians. Yet scenographic practices - including set, costume, lighting, sound and visual projection/video designs - are fundamental for the construction of essential (dis)orientations without which in fact no performance would take place. Designing a space for performance sets up the crossing of thresholds, throws the engines of engagement into gear by precipitating the trust, the expectation and anticipation we bring to a space, the knowledge we have of a space and the "tacit agreements" with which we behave in it (Newling 2007). The scenographic manipulation of physical materials and the visual and aural aspects of performance may appear to have had secondary (technical) status within the field of theatre, performance and dance studies. Not only recent debates on the "postdramatic" (Lehmann 1999/2006; Worthen 2008), however, but the general impact of media on our cultures along with the surge of digital practices, social networks and internet platforms, provoke fresh interest in the contingent "object" of performance, the mise en scène of remediation and re-mix, in staging processes which draw on the expanding repertoires of digital media. 
Today, in a new century considered to be an advanced technological era of pervasive computing and networked connections, questions of space and movement hold crucial challenges for interaction designers and architects, and for those of us working in performance design with real time interfaces and immersive digital projections (video, sound, animation, 3D graphics, virtual realities, networked transmissions, etc). The question of immersion needs to be addressed urgently, as there are some myths flying about that may need debunking. Are there any fully immersive virtual reality performances available to the broader audience, or are such complex artworks (using stereoscopic VR head mounted displays for a single user who navigates inside a 3D computer graphics world) exceptional instances, such as Char Davies' Osmose, and limited to CAVE virtual reality environments and electronic visualization labs? Has interactivity brought about new conventions of digital mise en scène? Has the increasingly commonplace use of video projections in contemporary stagings replaced the need for material sets and objects? Is it a fair assumption, expressed by the editor for this journal, that the adoption of digital media across the field of performance arts can generate alternative materialities that either disrupt existing scenographic practices or perpetuate established practices through new means?

In the following, taking my cue from the traditions of Japanese prints (ukiyo-e) mentioned in the beginning and describing the choreographic installation UKIYO created by our DAP-Lab ensemble, I will approach some of these questions by reflecting on a few mediums (of performance) or "pictures" of mediums, drawing attention to the temporal meaning of mise en scène, and thus particularly on compositional process (mettre en scène) and our fashionable adoptions of technologies. Our Design and Performance Lab, associated with Brunel University's Center for Contemporary and Digital Performance, conducts research into interactional and wearable technologies, and UKIYO is a project created in partnership with artists and researchers in Japan. DAP's production company performs or exhibits works in professional and academic venues.

New media in performance are fashionable. Many producers of hybrid works promote them, and thus frame their reception, by drawing attention to the deployment of this 
or that "cutting-edge" tool (wireless sensors! real-time motion capture system!) and the "how" rather than the "what." This has been a trend amongst dance technologists and installation artists who, in some cases, now also list the software amongst the various design credits. Pablo Ventura’s recent performance, «2047», for example, mentions Life Forms, ISO [Interactive Swarm Orchestra], Max/msp, and SoftVNS3. While such attention to the engineering and systems design of a work is interesting from a technical point of view, it is a poor reflection of the content of a work and deflects from the need, generally felt now amongst curators and producers, to expand critical frameworks for aesthetic criteria, to examine interactive, real-time or hybrid scenographies in performance not only in terms of their function but also in their thematic, social, contextual and psychological dimensions, including the observed behaviors of audiences no longer contained in passive receivership. Action and agency (terms derived from social theory and games theory) move to the foreground. If an installation is created for an immersive or mixed reality experience - using actual and virtual representations of characters and space - one would need to discuss how the relations between actual and virtual enactments, and between such different levels of (re)presentation and the audience are formed, and how they are perceivable and experienceable.

"Floating" became the conceptual metaphor for our production. In order to create a "moveable world, " we worked with three primary dimensions; (1) movement environment (spatial design); (2) movement images (projections of digital objects and virtual spaces); (3) movement of sound (from macro to micro levels). Floating the audience implied dissolving any borders between stage and auditorium; we used this concept along with the ideas behind our wearables (intelligent garments) used in previous design-in motion performances. In our previous production, Suna no Onna, we had worked on composing "wearable spaces" for the dancers on stage (Birringer/Danjoux 2008). Our ideas, derived from fashion design, film, dance, and real-time sound processing, focus on developing narrative materials, characters and actions which can tell a story in a particular digitally projected environment programmed to behave in response to expressive input from the dancers. The environment has a character (or multiple characters) too. It is subject and object, a Floating World moved into relationships with pictures of such "ukiyo.” Imagining a 
space that can be worn, in the sense in which a performer can model and transform a costume or become a mask, thus meant taking the digital phenomena almost literally as actors, as living states of being and as being transformable (data) objects. As we understand digital performance, the visual and auditory dimensions of a work - and its entire sensorial impact marked by audio-visual tactility, plasticity, intensity, color, and multiple kinetic tonalities, rhythms, and pulsations of movements and imageforms - are continuous, evolving relations between the physical and the virtual in a space that never stands still and has no (single) dominant perspective.

\section{Scenographic process}

The design of the environment was the starting point. After studying the Japanese prints and noticing the frequent use of Kabuki actors as subject of the pictures, I became fascinated by the hanamichi (runways) of the traditional Kabuki theatre, and proposed to create an open space that would have five hanamichi forming an irregular pattern. As a first step, then, we created a model of the criss-crossing hanamichi, imagining the runways to be white dance floor strips on a black floor. Initially the runways would be flat, in later versions we might want to make them more dynamic by raising some of them slightly or creating irregularly ascending or descending trajectories. The runways are the primary movement areas for the dancers and the character they create. Throughout the duration of the installation, the performers would be with the audience in the same large space, and on occasion "enter" the runways or occupy them, allowing the audience to follow them or observe them from any point in the space. The digital scenography extends this space into the virtual on and off-stage spaces which are visual diegetic (narrative) spaces dialectically enhancing the imaginary world of the performance as a whole. The production thus creates a more demanding layering of simultaneous perspectives; all digital "objects" were to be mixed and synthesized in real-time.

The reference to the hanamichi, on the one hand, places our spatial vision for the work into the context of Japanese Kabuki theatre and the preoccupation that the ukiyo-e artists of the $18^{\text {th }}$ century had with so-called actor prints, portraits of wellknown Kabuki actors. Muto Junko suggests that these prints were often created in 
direct reference to particular plays and the actors' appearance in a scene that could then be recalled and re-heard by audiences who knew the performances of characters (and the particular acting style used by actor families who passed down the style from generation to generation) - and most strikingly Junko speaks of "hearing the prints" depicting a scene voiced and danced to joruri music (Calza 2005: 10-11). The calligraphy on the prints depicting the actor en-scène would help the viewer to recollect the particular dance and stage speech. In Kabuki theatre, of course, the particular function of the hanamichi was to cut right through the audience, thus serving as stage and as passageway, bringing actors and audience together in one space. For the scenographic sketches I developed, and the characterizations effected by Michèle Danjoux's conceptual fashion design, the hanamichi were also envisaged as runways.

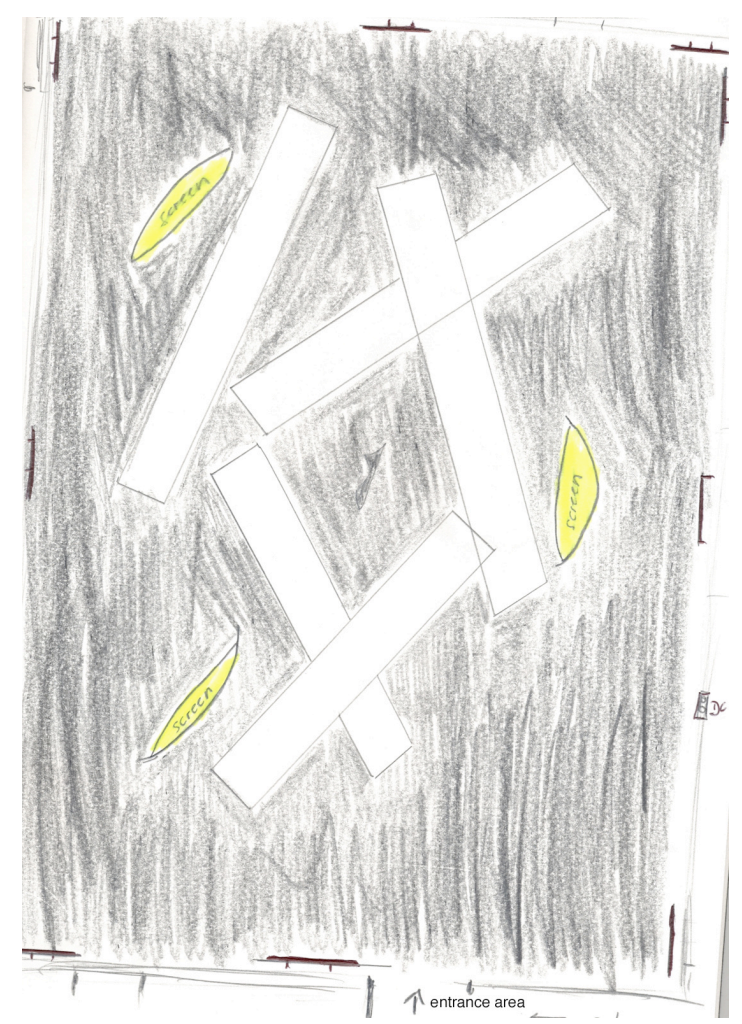

Fig. 1 Drawing of UKIYO performance environment @ DAP Lab, 2009. 


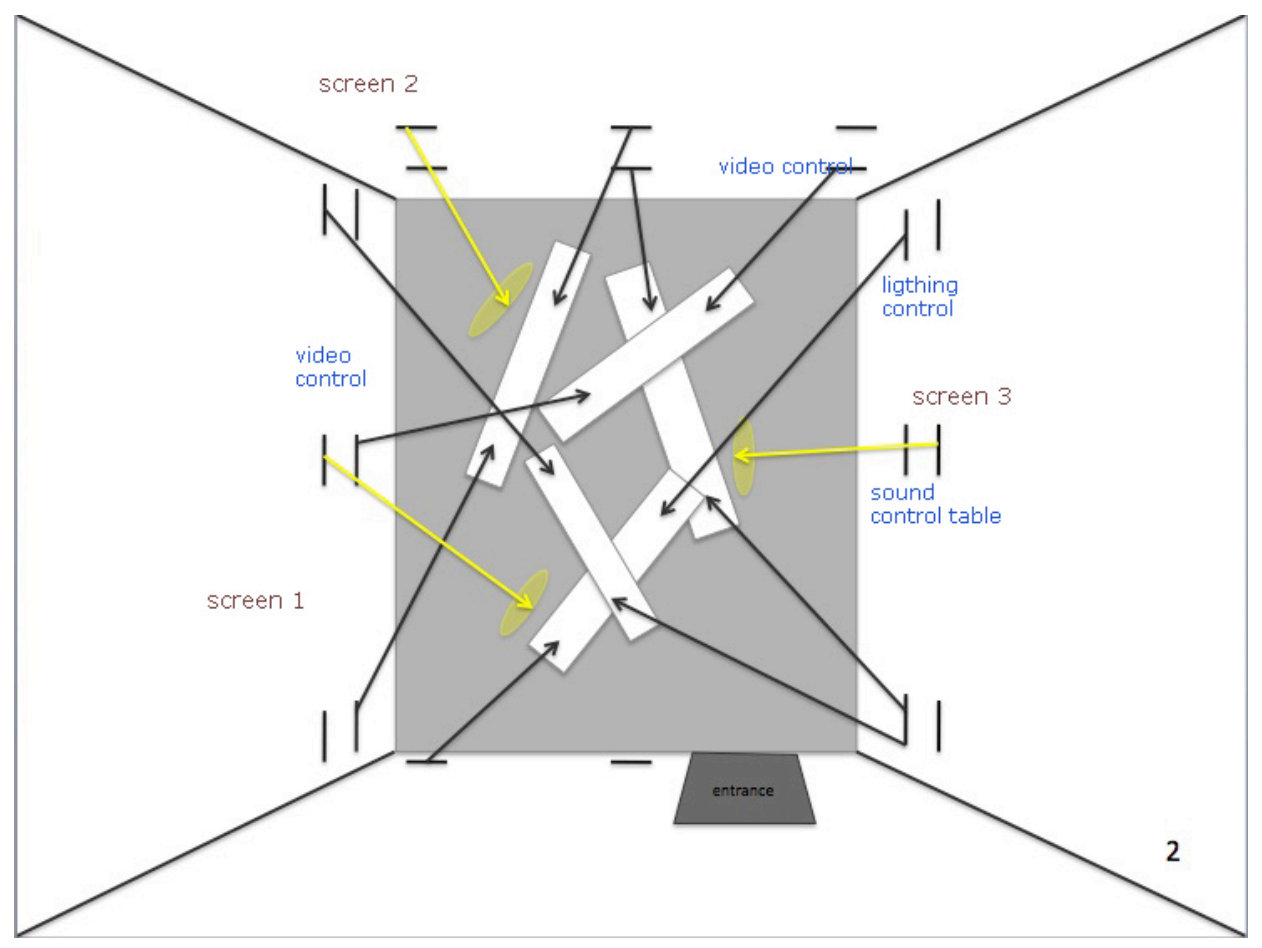

Fig. 2 Computer rendering of UKIYO performance environment for lighting plot (C) DAP Lab, 2009.

From a bird's eye view, the five hanamichi were also a symbolic character in itself: I wanted to evoke an abstract labyrinth that drew the audience into a system of corridors to which we alluded in the opening (projected) titles that appear on the three suspended screens. The screens were raised 2.5 metres from the floor and suspended from the grid, forming an irregular triptych for rear projection. On these screens the projected still or moving images unfold, in black and white and in color. Many of the images we shot are in fact "portraits" of our performers, composed in the studio or in outdoor locations. Some of the diegetic images are historical photographs - found objects recomposed into short animated films or layered into composite portraits/landscapes. The runways are white and thus allow special lighting to illuminate them or color them for the scenes of the dancers' performance, which we choreographed as a series of solos (following a particular code of costume colors red, white, black/grey, silver, golden), and then as increasingly overlapping and simultaneous duets, trios and quartets that phased in and out of the fluid action as well being woven into the sonic environment created by the composer and the performers themselves. We did not choose a Kabuki play but created a dramaturgy based on choreographic motifs and the development of particular characters chosen by the dancers in response to some of the images I had brought to rehearsal. 
For the scenographic process, these images were crucial: they were our "audible prints," so to speak, and the prints I chose refered to early $20^{\text {th }}$ century revolutionary communist history and the beginnings of the $20^{\text {th }}$ century modernist avant-garde. Our source materials were the media-archaeological research by Siegfried Zielinksi, especially his vivid writings on Russian engineering and motion study in Deep Time of the Media: Toward an Archaeology of Hearing and Seeing by Technical Means, and Christian Kracht's dystopian novel Ich werde hier sein im Sonnenschein und im Schatten - a surreal work depicting a century of (post)revolutionary process stretching geographically from Africa to Mongolia via the secret hiding places of the military engineers in the Swiss mountain Réduit. The archaeological theme here connects Russian engineering feats with the transrational poetry (onomatopeia) of Velimir Khlebnikov, Aleksej Kapitanovich Gastev, and Alexei Elseevich Kruchonykh, the audacious protective space suits of Cold War fashion, and the fictional virtual language investigated by officer Brazhinsky in Kracht's novel. Since our ensemble had worked with dresses incorporating wireless sensors before, with garment and physical motion affecting the digital projection environment, I became attracted to the new language of communication Brazhinsky calls "smoke language" (Rauchsprache). I quote the passage that we used as intertitles in the Entr'acte that bridges Part 1 and Part 2, a silent movie shot in black and white with two actors appearing on facing screens:

Language is a collection of symbolic sounds, it originates in a cosmos of unrecognizable forms - which are above all, never knowable.

But please explain to me - how does the smoke language function?

Well, we begin to speak what we think, we place it into the space. Then we can look at the spoken, we can walk around it, and finally we can move it. Since it exists, we can move it.

(Kracht: 43-44, my translation)

The plasticity of (design) languages lies at the heart of our performance, and we deliberately relinquished any overt reliance on direct interactivity that relies on software programs registering data transmission (input) and generating reactions in the environment (output). Such a system of mapping is always limiting to the 
complex wholeness of visual, kinetic and auditory/vocal movement, since the dancer in interactive performance systems needs to pay undue attention to the quantitative motion or acceleration/deceleration. UKIYO questions the very stability or recognizability of symbolic forms that a software might operate upon within the overall performance system; when we thought of data or numbers, we tended to think of them in plastic and musical terms. Heterogeneous design inspirations were brought to the scenographic, choreographic, filmic and musical process our ensemble engaged; composer Oded Ben-Tal, for example, conducted early experiments with percussive gestures which we motion-captured to obtain data that could be used for the kinaesonic aspects of the real-time projection environment we were building. The kinetic data were to be combined with the physical sound gestures the dancers performed in the space, but we later decided not to use the motion capture data since the acoustic and live electronic performances created much stronger plastic and sensual rhythms than we could achieve by triggering digital data effects. Kinaesthetically and proprioceptively, gestural interactivity with real-time environments (sonic or visual) can deflect both from the physical virtuosity or embodied expressiveness of the performer and from the unpredictable qualities and metaphoric richness of moving digital scenographies (films, layered animations, networked video streams). There was no reason - in the poetic context of our performance - to work with direct mapping and causal feedback, to move according to software parameters. Our audience was to experience "moveability" as a virtuality that was not overdetermined, in the sense in which digital programs determine, for example, the principal directions and speed of images: forwards, backwards, slow, fast. We wanted indirect relationships to happen, to surprise us in a polyphonic manner, as if sound and voice were to transcribe, counterpoint, and also decenter the visual medium (cf. Birringer 2008a: 153-64).

One particular key idea for the costume design was Danjoux's plan to build small speakers of various sizes as sound transmitters into the garments, and to explore the visual aesthetic of audio technology. One of the dancers, Anne-Laure Misme, was given a set of inverted, dysfunctional speakers to wear on her breasts; another dancer, Helenna Ren, performed a choreography with two larger, sound emitting speakers which she balanced on a yoke placed on her shoulders. Caroline Wilkins performs live on an amplified bandoneon in Part 1, while in Part 2 her entire dress is designed 
as a bandoneon opening up and revealing, down her spine, a black leather strip with built in speakers. Ren and Wilkins thus perform with wires, their amplified body/instruments connected to the sound system and into the sonic and image processing environments performed live by Ben-Tal, Paul Verity Smith and myself on the computers. Analogue and digital processes, in which the sound-gestural choreography interacted with the visual and audible scenography, with sonic diffusion, progression and image-movement in the projected environment as a whole, combined to create what we thought of as the 'curves' of UKIYO
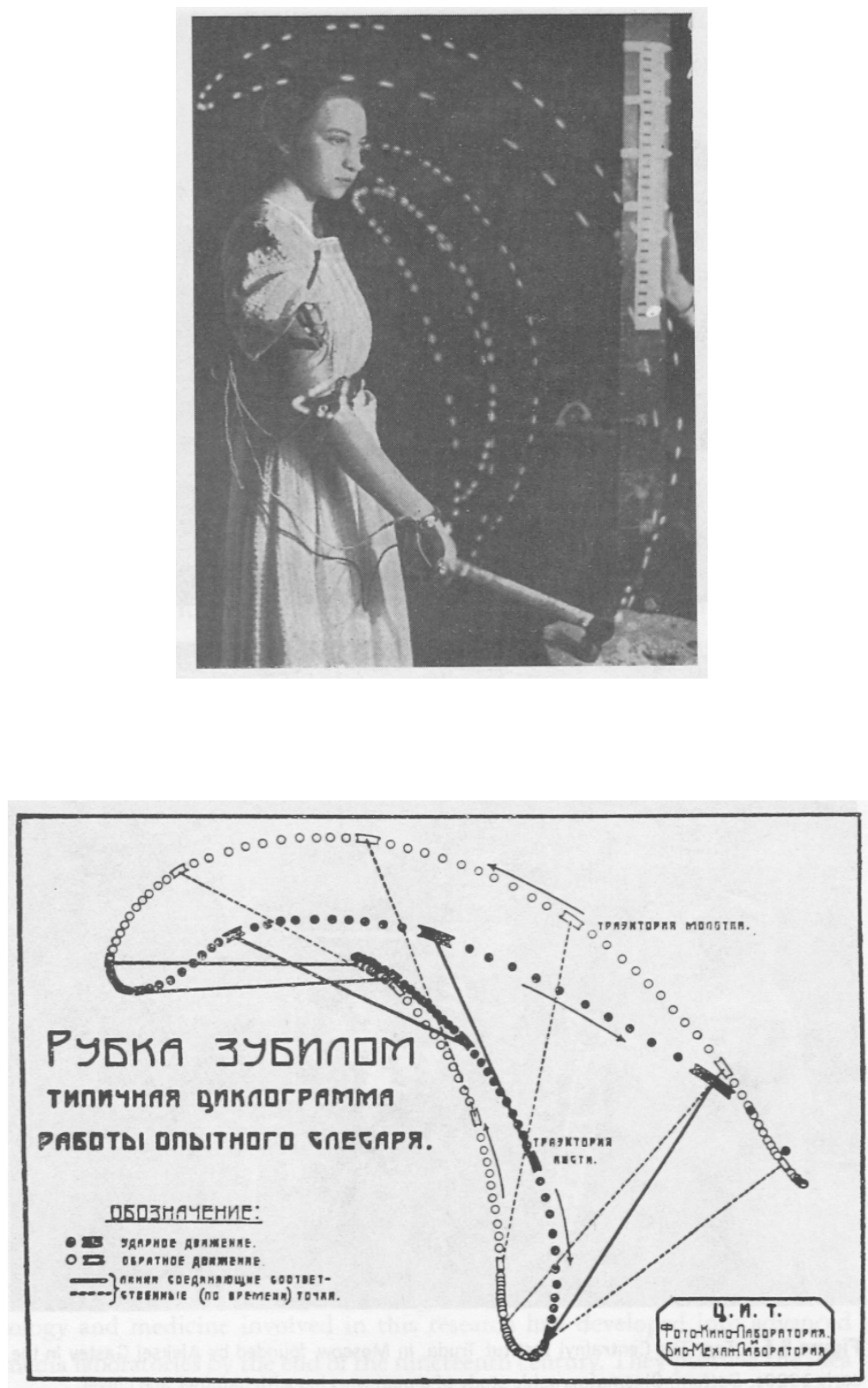

Fig. 3 \& 4. Top: Strike and pressure: A demonstration of the chronocyclographic method on Gastev's Moscow Institute (C.I.T) by a female worker with an artificial arm. Two photophorescent dots are fixed on the hammer so that the movements can be recorded photographically as curves. On the right 
side of the picture an assistant holds a measure to provide a scale. Bottom: Diagram of the movements of a worker wielding a hammer. (C) 1926 R. Fülöp-Miller, Geist und Gesicht des Bolschewismus.

We had already planned, at the early stage of our designing process, to collaborate with our partners from Keio University (Tokyo), and had exchanged ideas about how mocap data might be usable in UKIYO to link the real space thematically to the virtual environment, or to generate choreographic processes that might flow between RL and Second Life, the material world and the immaterial synthetic metaverse. We began our collaboration with several telematic sessions during which we streamed camera-based film images of the "WorkerWoman" between London and Tokyo, conjoining the hands and arms of Helenna Ren (in the London studio) and Ruby Rumiko Bessho (in the Tokyo studio). The WorkerWoman was our first character,

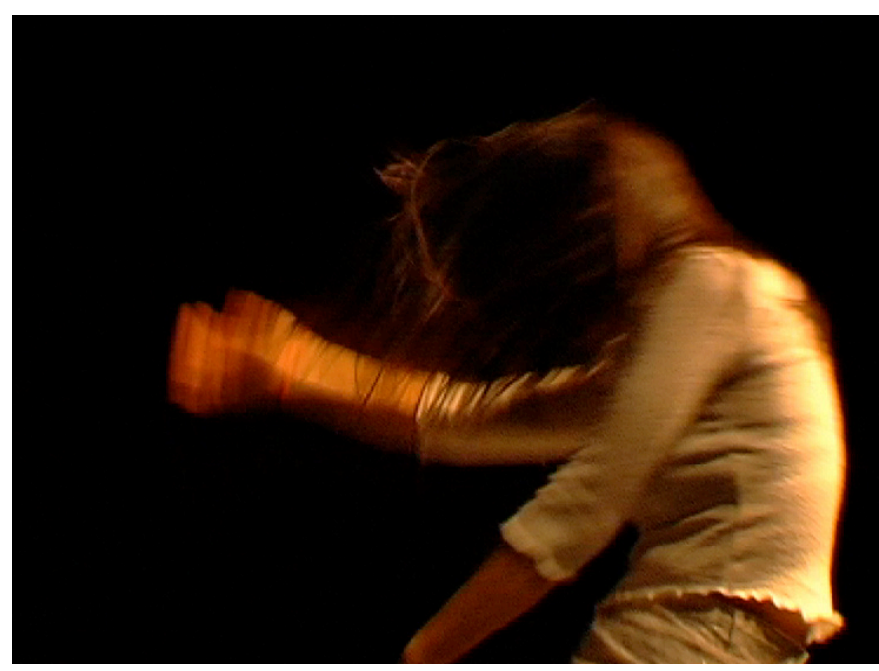

Fig. 5 Helenna Ren and Ruby Rumiko Bessho, Hands-Dance (C) 2008 DAP-Lab.

setting in motion some of the other scenic materials we developed over the autumn, winter and spring of 2008-2009 - and here the development was closely pursued in relationship with musical ideas, movement ideas, and the design concepts Danjoux proposed for the wearable garments capable of generating sound or incorporating audiophonic instruments. Our moveable virtual world was to be "sounded" by the 


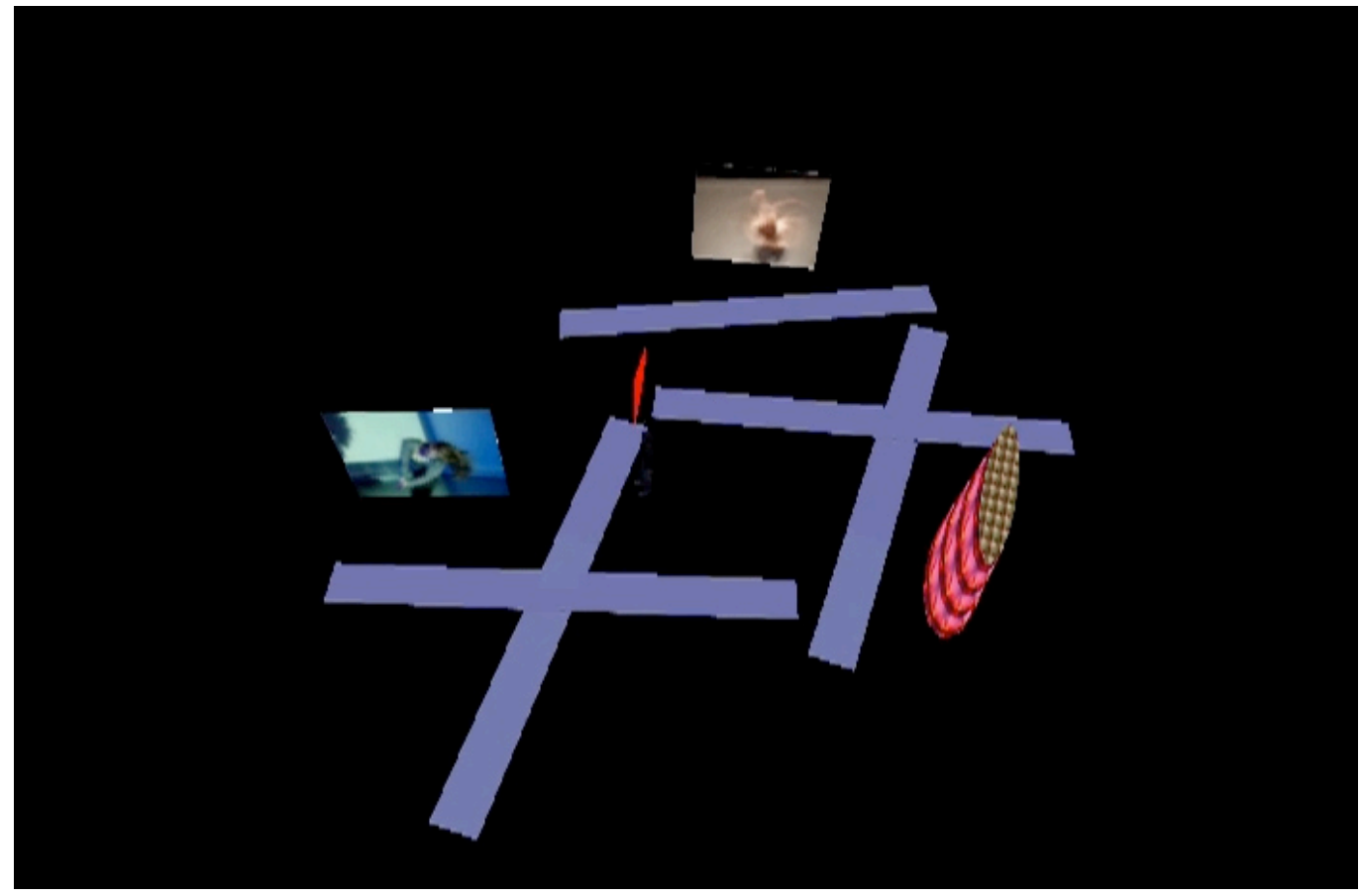

Fig. 6 Model of UKIYO virtual space in Second Life (C) 2009 Courtesy of Kabayan/Inetdance.

gestures and clothes of our dancers, and the behavior of avatars in the virtual world, in return, would slowly begin to act upon the movement vocabulary of the dancers in real space.

The challenge we faced was the "modeling" of the virtual world upon the material space; our Japanese partners proposed a "real" model of the scenographic drawings I had made, mapping the space in Second Life according to our physical environment, and using the screen spaces inside Second Life UKIYO as portals to the networked dance sent via live video streams. In this manner, the Japanese dancer in Tokyo could in fact perform in real-time with our physical performance in London, projected via the Second Life virtual environment into our digital mise en scène on the ground (or rather, above the ground, suspended). This is perhaps a basic definition of what we mean by digital scenography: the live performance architecture incorporates analogue, digital and networked dimensions: performers and audiences are inside and outside the digital worlds simultaneously, and the screen canvases co-animate the localized movement narratives, as much as the movement characters and costume designs animate the images from the past and present, and even forecast the meanings that might be read into the dancing language of the avatars, their bodies, sexualities, identities. Such hybrid spaces can evoke forceful and beautiful combinatorics, fusions 
of the expressive and intuitive with the logical and cool computational circuitry, the subtle bodily rhythms with the brittle digital graphics, mundane flesh with extravagant avatar torsos. Much could be said here about the nature of "digital space" or virtual environments, if one were to follow Deleuze's writings on the time-image (in cinema) into the hybrid chronological and non-linear temporal coordinates of digital aesthetic production with multiple vectors of distributed space (Munster 2006: 172-73). If we think of stage design as grounding visual information (setting, place, context, etc), then our scenography behaves more like the Flash web interface design Munster examines in her writings on digital materiality and the deformations/compressions of image information. Rather than delimiting spatial location, or providing spatial configuration and "scenery," it behaves as a smoke language in the manner we reimagined Kracht's poetic evocation: we can walk around it and see it evaporating and re-emerging, layered pictures of photounrealism mutating into visually flattened animé or jumpy avatar motion in Second Life, unlifelike physics chaotically out of world and too slow or too fast. Scenographic behavior - not to use the fashionable term "emergence" here - therefore is a crucial aspect of our production. The digital mise en scène does not represent the absolute speed of revolutionary modernity nor contain the Kleistian marionettes or machinewomen (e.g. Fritz Lang's Metropolis) or manga killer vamps but acts as shifting disparities, graphic intimations of failed biomechanism that humorously distract from the physiological and psychological dimensions of the labor performed by the dancers.

The choreographic installation was first performed on June 1, 2009, in the Artaud Centre, and as you can see in Fig.7, the positioning of the screen spaces caused problems and will be revised in future performances of the work. The Artaud space ( $21 \times 15 \times 10$ metres) was perhaps too large for three hanging projection screens $(2.80 \mathrm{x}$ 2.30 metres). On the other hand, the projected spaces in this way also did not overpower the physical arrangement; there was much space to breathe, and to move. No attempt was made to use projection as backdrop or as "extension" of the stage space, as we often see it in contemporary theatre and dance productions in proscenium spaces. The "virtual scenography" for UKIYO has a sculptural character but also needs to be interpreted as a necessary compromise, perhaps even a limitation: 
the digital visual dimensions rely on points/positions in space, planes that vertically cut into the larger volume of the hall. The audience is not immersed at all in a virtual reality, but can well distinguish between the material space and the projected digital worlds, windows into worlds consisting of digital video, computer animation, still images and Second Life streams.

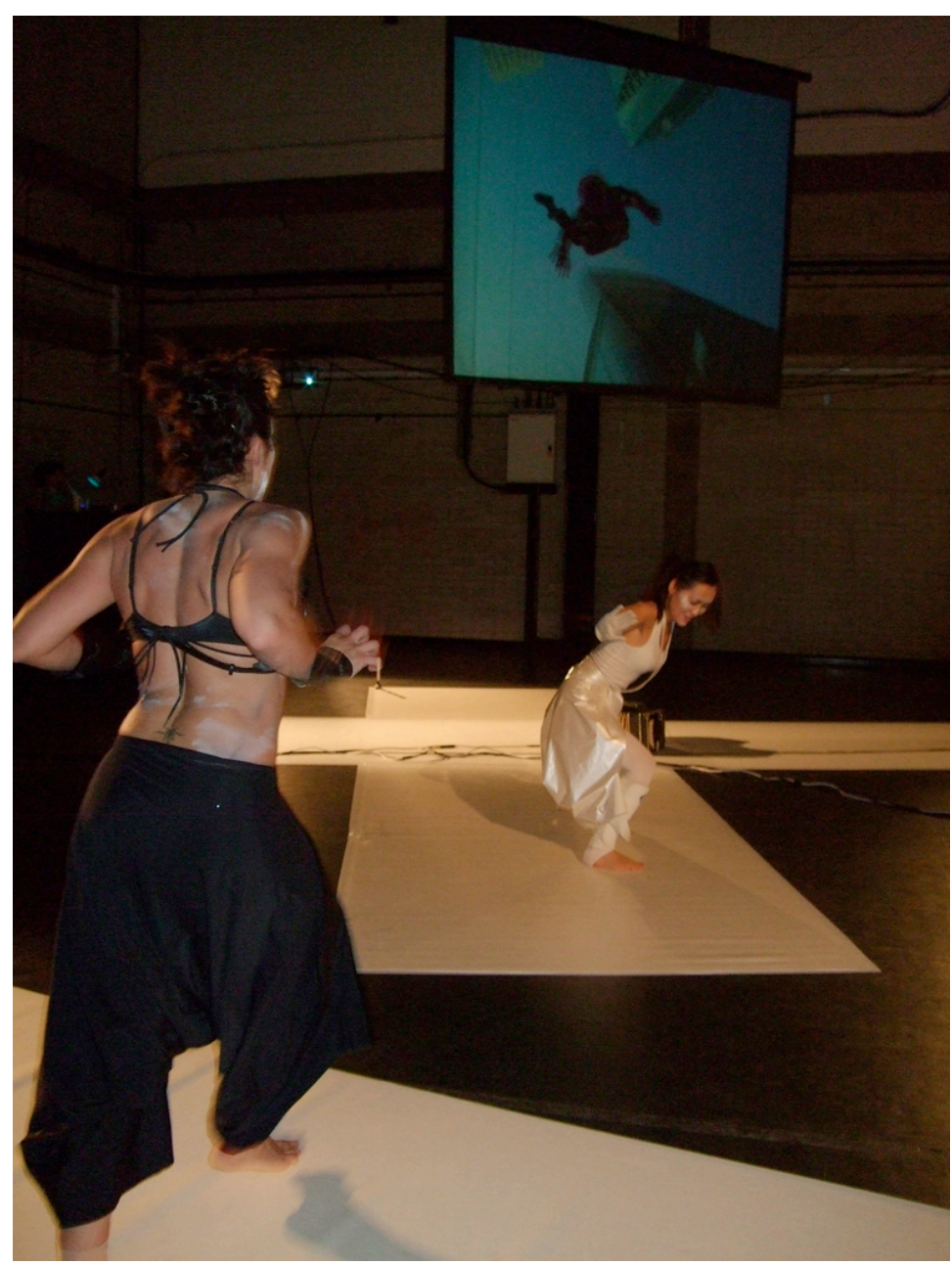

Fig.7: Rehearsal for UKIYO, with Anne Laure Misme, Helenna Ren $\odot$ 2009, DAP-Lab/dans sans joux

\section{Sound-theatre in real space}

The scenography for the real environment was straightforward. The five hanamichi were the material space for the movement characters; all garments and objects used in performance carried a strong sensual presence and plasticity, especially as the performers increasingly drew the audience closer to their actions, with members of the audience walking around and across the space, often coming into very close, intimate proximity with the dancers. The creation of sound performance was a leitmotif for UKIYO, in the manner in which I just referred to the physiological and 
psychological dimensions of labor processes. The characters - we named them InstrumentWoman, SpeakerWoman, HammerWoman, WorkerWoman, BirdWoman and MutantWoman - carry out motion sequences that produce sound through the garment textures, objects, and small or large speakers manipulated by the them. A special emphasis is given to the gait and the manner of walking or acting with wired costumes that restrict motion to a few parameters.

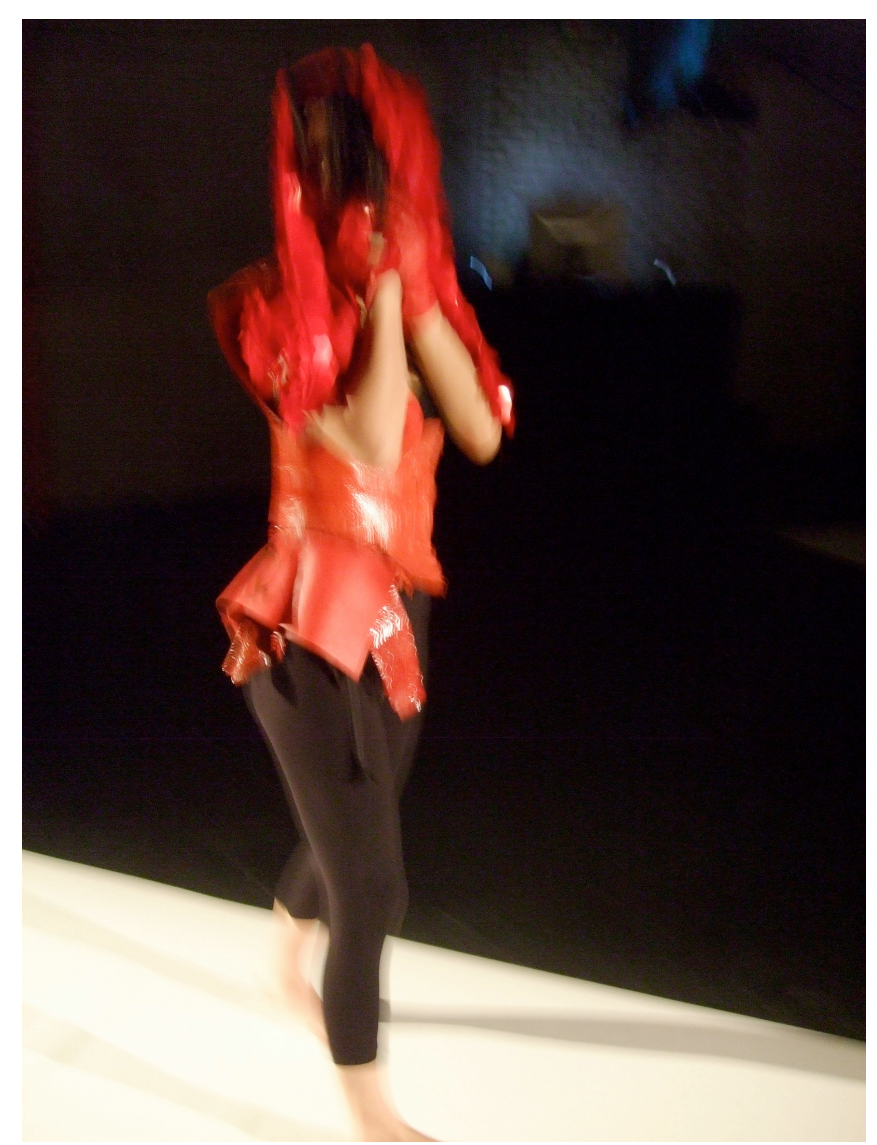

Fig.8: Katsura Isobe as MutantWoman in UKIYO @ 2009, DAP-Lab/dans sans joux

Such play with degrees of freedom heightens attention to the movement's microperceptual qualities, the small gestures and the relations opened up between different sound frequencies coming directly from the body or originating in the amplified ambient sound that enveloped everyone in the theatre space. The musicians and dancers in the ensemble worked particularly on the inside/outside auditory spaces and editing of sound, building a special series of sensory haikus that attract audience attention to the intimate sounds created organically. Michel Chion calls this "internal logic," when the sound-image develops, grows and is born out by the narrative 
situation itself and the feelings it inspires (visualized sound), whereas the "external" intervenes and ruptures the flow, often creating discontinuity or changes in tempo (Chion 1994: 46). In the hybrid design for UKIYO, Ben-Tal's digital sound also floods the entire space: it is acousmatic in the sense in which sound artists (after Pierre Schaeffer) understood such sound to be heard without seeing their originating cause, the emitters or instruments. Often such sound was made only for the recording medium, and for us the ambiguity of acousmatics was interesting since we explored the visible and the invisible, for example when Ben-Tal sampled the bandoneon. The tones played by Wilkins were recorded, but also the "breathing", when the instrument is expanded to take air in before pressing it out. Often the dancers are clearly visible as the subjective source for acoustic sound. Katsura Isobe wears a red sleeve design built out of small metallic plates that rustle when she moves to change shape. In some scenes, the spatial points of audition are mixed, for example when Ren's SpeakerWoman manipulates the speakers that emit electronic stereo sound and complement her own physical phrasing. Ren dances the image of a rice field worker, seeding sound in the earth. In contrast, Yiorgos Bakalos and Anne-Laure Misme perform to muted industrial factory sound, inventing a series of variations on the percussive gesture. 


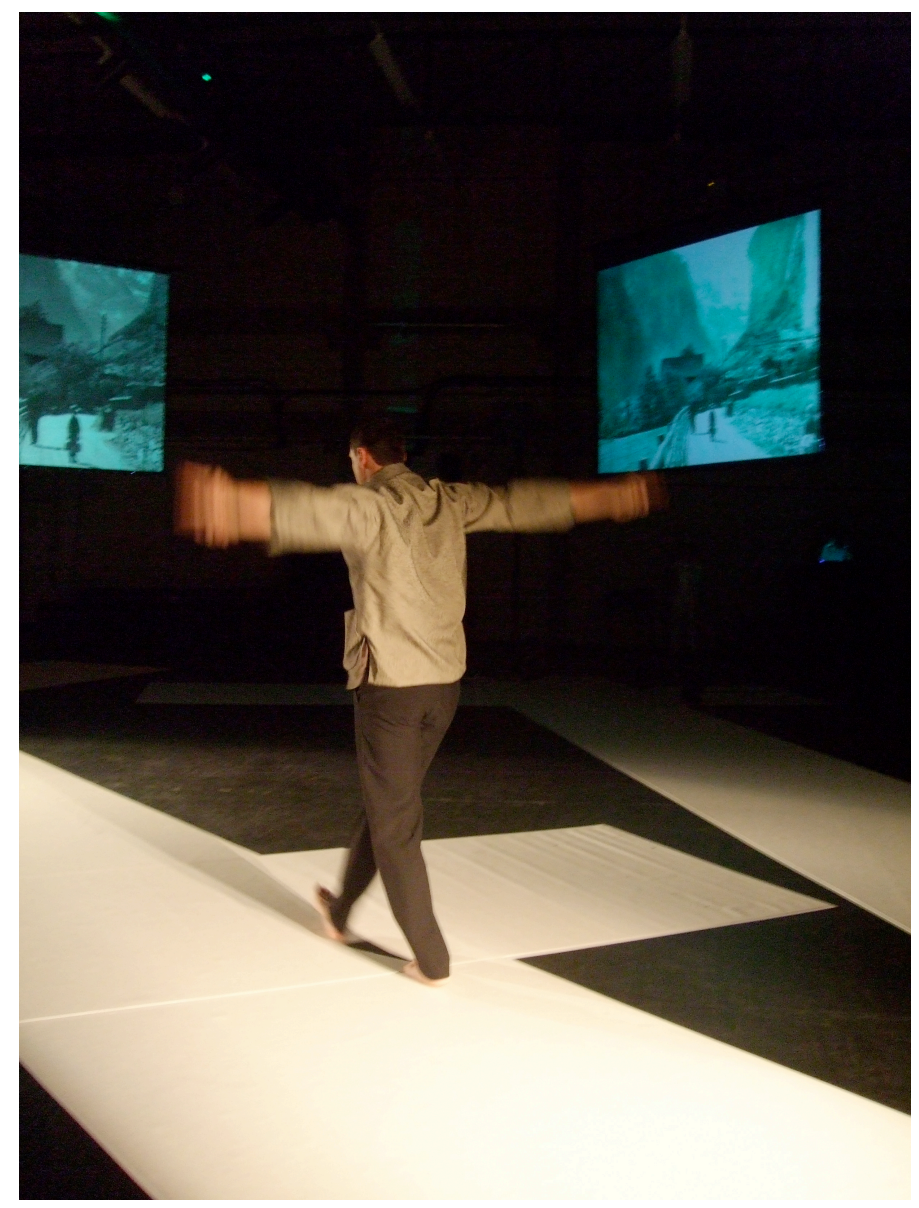

Fig. 9: Yiorgos Bakalos performing in opening scene of UKIYO C 2009 DAP-Lab/dans sans joux

At the end of Part 1, Wilkins performs the bandoneon lying horizontally on the floor, her instrument on top of her body as if growing from her, exfoliating, expanding and curving with her breath. The contact microphone on the bandoneon picks up microscopic sounds of air and breath, fingernails hitting keys and wood, and transforms them electronically into eerily high frequencies that hover in the space, then reverberate and fade out. Wilkins' instrumental music-theatre technique draws attention to objects/instruments and the relations between gesture, object, image and sound and how the sounding processes become perceptible. This exteriorization was beautifully translated in Danjoux's costume for Wilkins, worn in Part 2 after the silent Entr'acte. In Part 2 of UKIYO, the sound appears to originate in the Second Life 


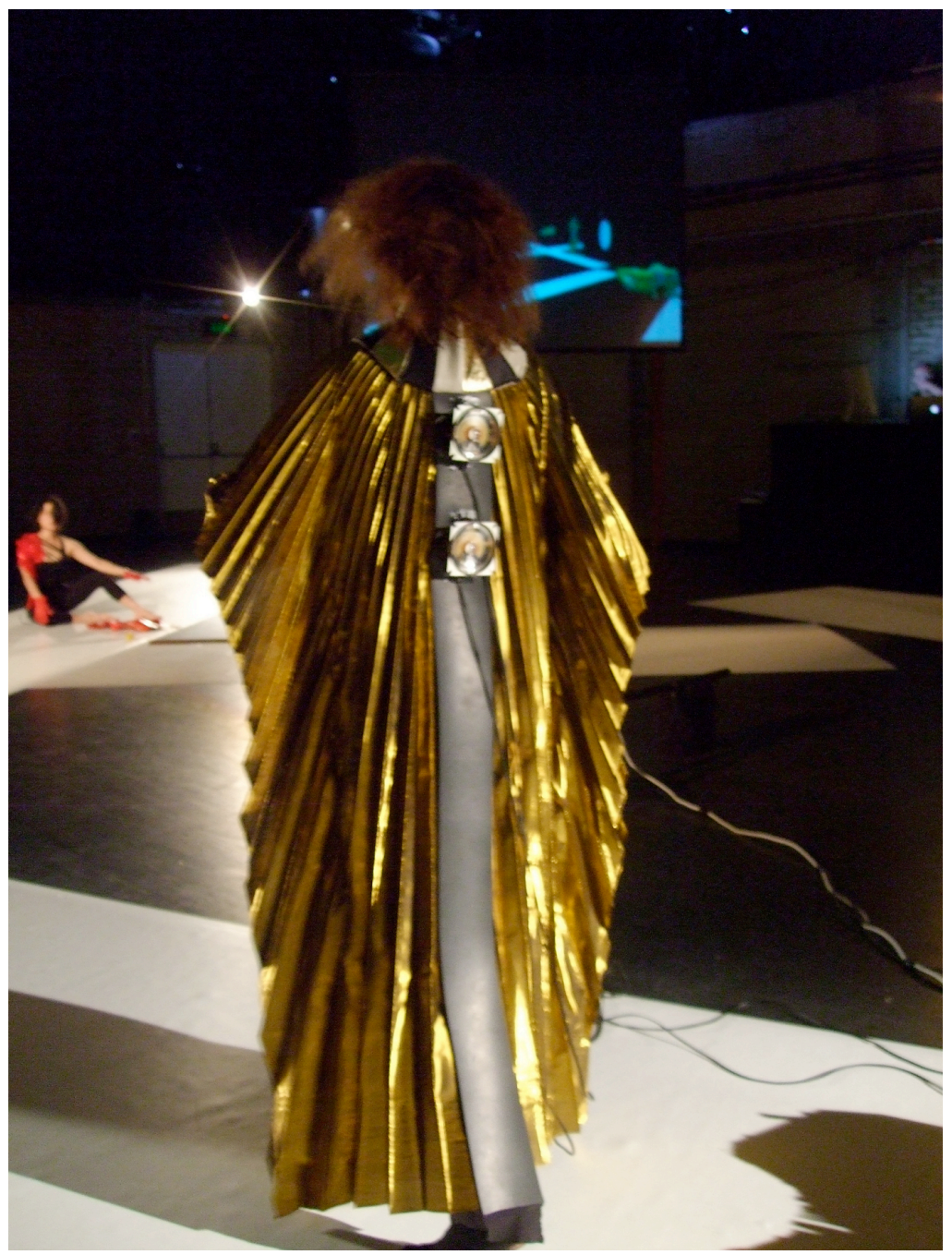

Fig. 10: Caroline Wilkins wearing BandoneonDress in UKIYO ( 2009 DAP-Lab/dans sans joux

virtual environment and is diffused around the entire space, as we hear the high frequency voice of a Japanese singer intoning a haiku (see below). Then the relationship between digital scenography, choreography and music shifts, and attention is refocused on the directional sound coming out of the small speakers in Wilkins' BandoneonDress which is constructed out of fabrics (white leather, golden silk, black neoprene) echoing the construction of the instrument. ${ }^{1}$ Wilkins now begins to use extended vocal techniques to instigate a scene of onomatopoeic soundmovement based on principles of call and response (gospel, jazz). This is the concluding scene of UKIYO, chaotically pointing to a sense of improvised

\footnotetext{
${ }^{1}$ In hybrid performance architectures that include interactive systems and real-time synthesis, it is problematic to use notions of preformed choreography; in such contexts the choreographic is partly improvised and partly structured yet open to instant transformations and adaptations. See "After Choreography" (Birringer 2008b).
} 
collectivity emerging from the world of the avatars into the real space, with audience members now dispersed all across the theatre, literally inside the hanamichi and brushing shoulders with the dancers, tuning into them or changing places with other audience members whose presence and articulated behavior have made themselves felt as well. The pluri-dimensionality of such a space, and the fragmentation of multidirectional perspectives (of moving-seeing, hearing, sensing), proffer an experience I also noted happening in Shift...Centre, a dance installation by Opiyo Okach presented at The Place Theatre, London, during the 2009 Dance Umbrella. The Kenyan company unravels the convention of spectating by creating a collective intensity of presentness that is, paradoxically, unfocussed; an incalculable number of events are generated simultaneously, small and big, noticed and unnoticed, each person in the room sees what speaks to them, "stumbles" across something, picks something up, follows a changing relation, not able not to move and participate in the immanence of the whole. The political dimension of such work might be subdued, barely foregrounded, but inevitably such physical musical performance provokes shifts in how we experience commonality and diversity (in his program notes Okach refers to lived multiple realities - "traditional African, Islam, Christianity, MTV...”). ${ }^{2}$ To allow for such affective instances of "social choreography" (Kozel 2008), where you become so aware of everything, the multiple viewpoints, the soft careful behavior of the audience members moving around not wanting to disturb another's concentration or enjoyment and in fact looking for that in the other people's eyes, the performance design may need to decrease the amount of graphic information and relent, let go a bit, trust the rhythms and sounds that make the room reverberate.

\footnotetext{
${ }^{2}$ For further information on Shift...Centre, see: http://www.gaaraprojects.com/shiftinggaarae.htm. Diametrically opposite to Okach's physical performance are examples of contemporary design which relinquish the physical altogether, as in Penelope Wehrli's camera orfeo installation (2008) which followed her pattern of the earlier video design for Bluebeard's Castle by removing all actors from the scene and replacing them with kinetic video-projective sculptures. Camera orfeo, subtitled "an autochoreographic and media composition," shows endoscopic images of the vocal cords of a singer while singing the aria "Possento spirito/Orfeo son lo" (Monteverdi) and, among other things, video images of dancers which are fed into a circular system controlled through the random movements of the visitors. The musical, choreographic and visual source material is continuously recombined and transformed into a kaleidoscope of images and sounds through the use of cameras that register what goes on in the exhibition and performance space. Benoît Lachambre and Louise Lecavalier's Is You Me (Coda Festival 2009, Norway), is a dance duet staged on an all-white raked platform which literally sutures the movement into Laurent Goldring's continuous and highly kinetic video drawings and graffiti projected live onto the dancers. Projecting visual graphics down onto the performers is a trend noticeable over the past few years; a prominent example is Glow (2007), created by the Australian Chunky Move company in collaboration with software engineer Frieder Weiss.
} 


\section{Virtual space: avatar choreography}

Part 2 of UKIYO visually folds the Second Life into the Real Life insofar as the computer-generated model in the virtual world and the animated choreography of the avatars now provide the framework for the unusual movement happening in the space. These virtual scenes, then, create a largely burlesque environment for the exploration of the "smoke language," setting up a rhythmic structure of short sung haikus that seem to propel the dance of the Kabuki avatars, computer-generated by our Japanese collaborator Gekitora. In the humorous (r)evolutionary logic underlying the scenes, the human workers in the bustling crowd of the collective learn the new movement management from the avatars, some of which step up to the edge of the screen to look out from their virtual world and monitor the adaptations by their disciples. We composed these scenes with a tongue in cheek reference to Khlebnikov's exhortation, in the prologue to Victory over the Sun (1913): "You, the people who have been born and are not yet dead"..."The theatre is a mouth! / Spectators, be an organ of hearing (be all ears) / And be observers."

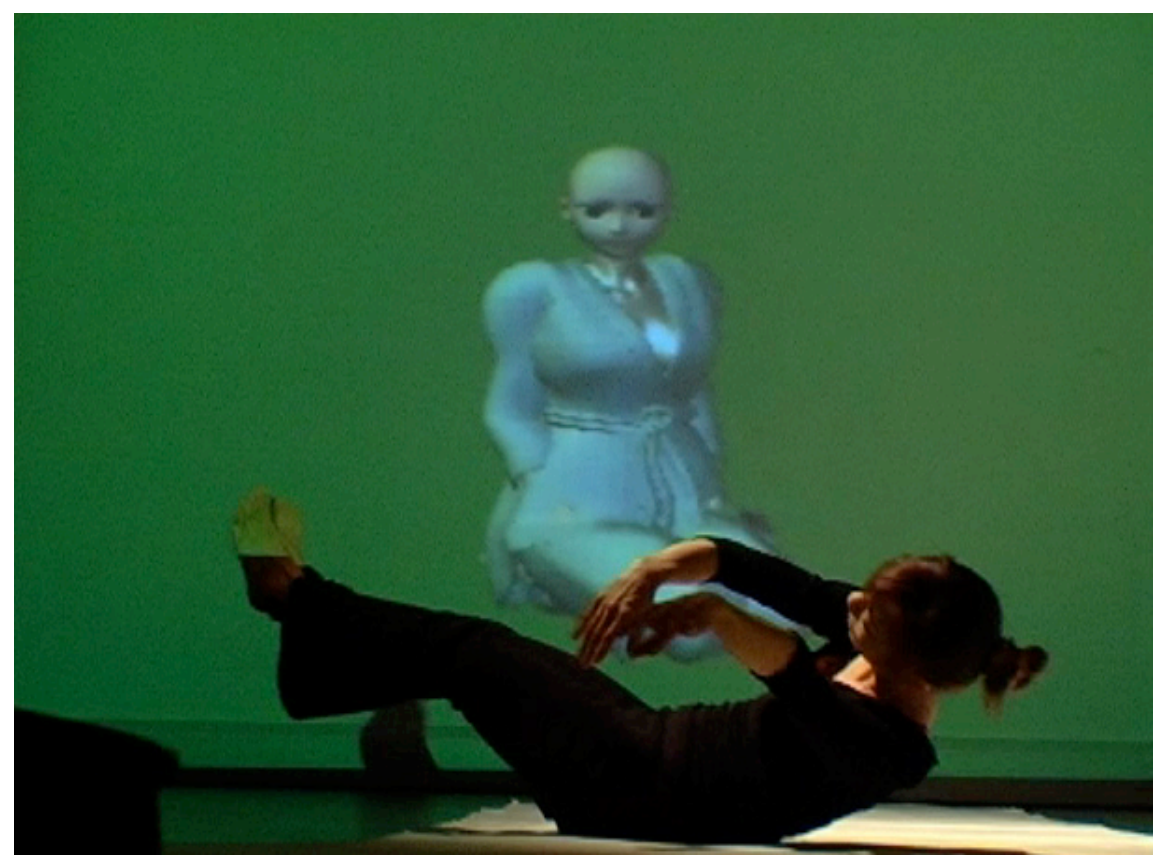

Fig. 11: Ginyuu avatar looking out at Ruby Rumiko Bessho in rehearsal for UKIYO ( 2009 DAP$\mathrm{Lab} /$ dans sans joux 
Towards the slow fade out of our performance, we imagined the whole space to have become a mouth, so to speak, with Wilkins intoning the birdlike trills and chants of her crazed interpretation of zaum, the transrational one word lines of poetry invented by Kruchonykh and Khlebnikov for the ecstatic cubo-futurist tone of their collaborative opera. The virtual environment in Second Life, meanwhile, had been opened to the public as well, and as I streamed the live sim of our virtual UKIYO onto the screens in our performance space, more and more visitors (rather, their avatars), were arriving and milling around.

Naturally, the avatars of visitors in Second Life could not experience our real space which had become a mouth. What they did experience was the rather more abstract modelled environment of the hanamichi and Ruby Rumiko Bessho's adopted choreography streamed up live onto the miniature screens in the virtual world. She interpreted the human adaptation of the Ginyuu avatar choreography and developed her own variation on it, responding as well to the feeling of the mouth she gained

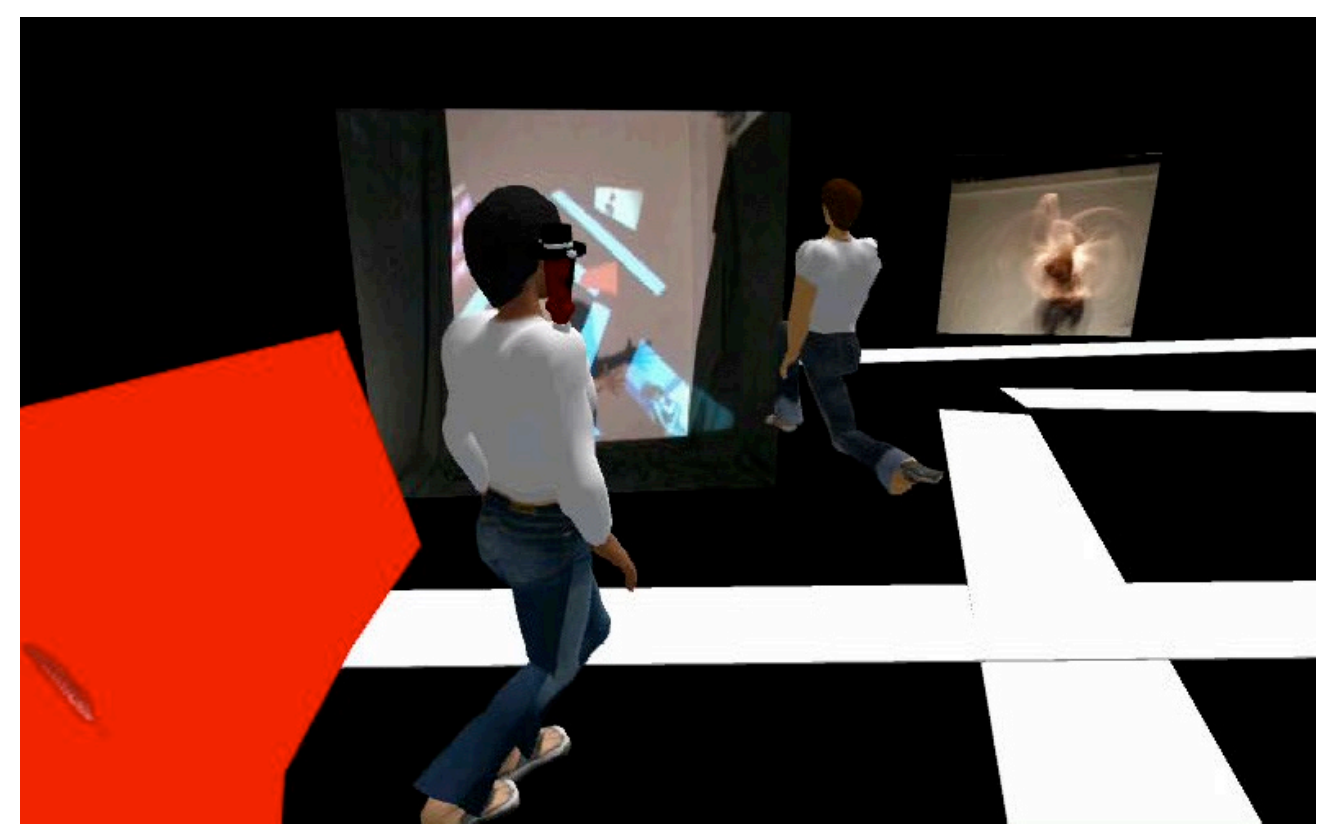

Fig. 12: Visiting avatars walking around the virtual UKIYO (C) 2009 Courtesy of Kabayan/Inetdance

from watching our performance via networked camera from my laptop (which also served as a communication/chat line to our collaborators in Japan during the premiere). At one point, I sent my own avatar into the SL environment to walk around a bit, while with my other hand I was activating a last animation sequence to appear 
on the screens - a cosmonaut-avatar stepping into space and slowly tumbling into zero-gravity, looking down at our mouth and the human audience that looked up, in a strange moment of shared perplexity, when certainties about what exactly constitutes reality, or "mixed reality," might be on hold.

\section{Mixed Realities}

Michael Takeo Magruder, a scientist/artist attending one of our workshops, talked about his conception of data environments, manifested in numerous installations that have received recognition, most recently The Vitruvian World and Data_plex (economy). He mentioned a 2007 commission (by Turbulence/New Radio and Performing Arts, Inc.) to a handful of creative teams to produce artworks that would engage users across three distinct environments: the online virtual world of Second Life, a traditional gallery space and the internet, via the Turbulence website. Magruder believes that art events of this nature will soon become relatively commonplace within New Media Art practice. He also suggests that "Second Life's accessibility and the user-centric nature of the environment opened new avenues to update and extend practice within the field of networked Virtual Art. Practitioners viewed the arrival of Second Life as a means to overcome the technological inhibitors of previous generations of Web and games platforms; their work would no longer necessarily consist of isolated virtual microcosms with limited or non-existent interaction between users" (Magruder 2009).

In the theatre world, involving a range of scenographic and digital design processes enacted by various artists coming together for a choreographic or musical performance, inhibitors still exist, since the notion of the user does not quite translate to performing artists working within existing dramaturgical and compositional frameworks of creation and public dissemination, nor does it translate to audiences either asked to spectate (for example, at a multimedia performance by the Wooster Group or La Fura dels Baus, or a multimedia theatre show directed by Katie Mitchell) or to participate in environments that might involve actor-audience interaction. Direct interaction would change our tacit agreements considerably, and I have not addressed this here. Referring to Second Life which houses the sim for The Vitruvian World, 
Magruder argues that this "fluid metaverse is the domain of its avatar inhabitants the projected extensions of a disparate collection of individuals channelling their consciousnesses into the shared environment" (Magruder 2009). A shared environment presupposes equal access and most likely a sustained involvement in its creative or other activities over a duration of time, and such can be the character of (net art) installations or networked co-authoring, but not of performances taking place on a particular day at a particular hour in a particular location, featuring trained performers interpreting a score (however this score has now become hybridized). The merging of UKIYO in London with a sims in Second Life was a one-time experiment that we have not repeated yet. The choreographic installation will be performed more often, in 2010, but cannot migrate to a networked site, as it needs the real-life performers in an actual, physically shared space.

For a digital scenographic practice that is not web-based but embedded in a physical theatre or performance venue, the hybridization of material design, embodied performance and 3D graphics or virtual world design requires specific compromises primarily the physical integration of projected 3D virtual environments - or any artificial life and AI system - into the time and spatial human-scale relations of an event, a gathering and its contingencies. Even more importantly, performer techniques need to co-evolve with interactive digital systems so that analogue processes - the vast range of human expressions and cultural perceptions - can thrive in computational climates. In curatorial terms, much debate is needed, and is taking place, for the creation of adequate conditions for the display of new media art installations. Such curatorial concerns are much less often addressed in performing arts contexts or venues (and academies that train the next generation of performers likely to work at some point with interactive, real-time technologies) needed to support research into, and implementation of, mixed reality design for/with live performance. We were fortunate, regarding UKIYO, that we had a university environment and facilities where such lab research could be conducted and a public performance produced, even if we lacked a lighting grid and the opportunities provided by advanced lighting technology. In our case, international partnership and cross cultural collaboration also required substantial funding, and careful coordination of rehearsal schedules over long periods, and therefore the organizational challenges 
for mixed reality productions are also substantial, as intermedia research and development take time, instruments and garments need to be built and tested, expertise in electronic engineering, computing science, network technologies, photography and film editing are needed along with proper networked studio facilities and equipment, so that performance/production roles and responsibilities for digital scenographies can be smoothly negotiated through the creative process. Nothing is ever smooth, of course, and artists and scientists are sometimes lost in translation. The community of digital practitioners is ever widening, of course, and the crossovers that Magruder mentions concern a much wider cultural base than the performing arts. The scenographic imagination for audio-visual design in the theatre can only benefit from this.

\section{Acknowledgements}

I wish to thank all members of the DAP-Lab/dans sans joux ensemble for their contributions to the project, and our Japanese partners for their roles in the collaboration. The first version of UKIYO (Moveable World) premiered at Antonin Artaud Centre, Brunel University, June 1, 2009, and the expaned work will tour Europe in 2010-11. Project website: www.people.brunel.ac.uk/dap/ukiyo.html. Label: www.danssansjoux.org

\section{References}

Birringer, Johannes (2008a), Performance, Technology and Science, New York: PAJ Publications.

Birringer, Johannes (2008b), “After Choreography,” Performance Research 13:1, pp. $118-22$

Birringer, Johannes, with Michèle Danjoux (2008), "Wearable Performance," Digital Creativity 20:1-2, pp. 95-113.

Calza, Gina Carlo, ed. (2005), Ukiyo-e, London: Phaidon Press.

Chion, Michel (1994), Audio-Vision, trans. Claudia Gorbman, New York: Columbia University Press.

Fülöp-Miller, René (1926), Geist und Gesicht des Bolschewismus: Darstellung und Kritik des kulturellen Lebens in Sowjet-Russland, Zürich: Amalthea. 
Kozel, Susan (2008), Closer: Performance, Technologies, Phenomenology, Cambridge, MA: MIT Press.

Kracht, Christian (2008), Ich werde hier sein im Sonnenschein und im Schatten, Cologne: Kiepenheuer \& Witsch.

Newling, John (2007, An essential disorientation, Warsaw: SARP.

Lehmann, Hans Thies (1999), Postdramatisches Theater, Frankfurt/M: Verlag der Autoren. Trans. 2006, Postdramatic Theatre, London: Routledge.

Magruder, Michael Takeo (2009), "The Vitruvian World: a case study in creative hybridisation of virtual, physical and networked space," in Franziska Schroeder (ed.), Performing Technology: User Content and the New Digital Media, Newcastle: Cambridge Scholars Publishing, pp. 51-71.

Manning, Erin (2009), Relationscapes: Movement, Art, Philosophy, Cambridge, MA: MIT Press.

Munster, Anna (2006), Materializing New Media: Embodiment in Information Aesthetics, Hanover: Dartmouth College Press/University of New England.

Pavitt, Jane (2008), Fear and Fashion in the Cold War, London: V \& A Publishing.

Worthen, W.B., 2008, “Antigone's Bones, “TDR: The Drama Review 52:3, pp. 10-33.

Zielinski, Siegfried ( 2006), Deep Time of the Media: Toward an Archaeology of Hearing and Seeing by Technical Means, Cambridge, MA: MIT Pres

\section{AUTHOR DETAILS}

Johannes Birringer is a choreographer and media artist. As artistic director of the Houstonbased AlienNation Co. (www.aliennationcompany.com) and DAP-Lab, he has created numerous dance-theatre works, theatre and video installations and digital projects in collaboration with artists in Europe, the Americas, Japan, Australia and China. He is the founder of Interaktionslabor Göttelborn in Germany (http://interaktionslabor.de). Recent productions include the digital oratorio Corpo, Carne e Espírito (2008), featured at FIT Theatre Festival in Belo Horizonte, Brasil, and the interactive dancework Suna no Onna (2007-08) presented at the Laban Centre and Watermans Arts Centre.His new choreographic installation, UKIYO, is created by his London-based research ensemble in partnership with Japanese artists. He is director of DAP-Lab at Brunel University where he is a Professor of Performance Technologies in the School of Arts. His latest book - Performance, Technology and Science - was published by PAJ Publications in 2008. 